\title{
Bedside nurses' roles in discharge collaboration in general internal medicine: disconnected, disempowered, and devalued?
}

Joanne Goldman, $\mathrm{PhD}^{1}$, Kathleen MacMillan, $\mathrm{PhD}$, RN, FAAN², Simon Kitto, $\mathrm{PhD}^{3}$, Robert Wu, MD ${ }^{4}$, Ivan Silver, MD, Med ${ }^{5}$, Scott Reeves, $\mathrm{PhD}^{6}$

1. Centre for Quality Improvement and Patient Safety, Faculty of Medicine, University of Toronto, Toronto, Canada

2. School of Nursing, Dalhousie University, Halifax, Canada

3. Department of Innovation in Medical Education, Faculty of Medicine, University of

Ottawa, Ottawa, Canada

4. Department of Medicine, Faculty of Medicine, University of Toronto and Division of General Internal Medicine, Toronto General Hospital, University Health Network, Toronto, Canada

5. Centre for Addiction and Mental Health, Department of Psychiatry, Faculty of Medicine, University of Toronto, Toronto, Canada

6. Centre for Health \& Social Care Research, Faculty of Health, Social Care \& Education, Kingston University \& St George’s, University of London, London, UK

Corresponding author

Dr. Joanne Goldman

525 University Ave., Suite 630, Toronto, Ontario, Canada, M5G 2L3

Email: joanne.goldman@utoronto.ca 


\begin{abstract}
Collaboration among nurses and other healthcare professionals is needed for effective hospital discharge planning. However, interprofessional interactions and practices related to discharge vary within and across hospitals. These interactions are influenced by the ways in which healthcare professionals' roles are being shaped by hospital discharge priorities. This study explored the experience of bedside nurses’ interprofessional collaboration in relation to discharge in a general medicine unit. An ethnographic approach was employed to obtain an in-depth insight into the perceptions and practices of nurses and other healthcare professionals regarding collaborative practices around discharge. Sixty-five hours of observations were undertaken and twenty-three interviews were conducted with nurses and other healthcare professionals. According to our results, bedside nurses had limited engagement in interprofessional collaboration and discharge planning. This was apparent by bedside nurses' absence from morning rounds, one-way flow of information from rounds to the bedside nurses following rounds, and limited opportunities for interaction with other healthcare professionals and decision-making during the day. The disconnection, disempowerment and devaluing of bedside nurses in patient discharge planning has implications for quality of care and nursing work. Study findings are positioned within previous work on nurse-physician interactions and the current context of nursing care.
\end{abstract}

Key words: interprofessional collaboration, interprofessional care, nursing, discharge planning, acute care, ethnography 


\section{Introduction}

Hospital discharge planning requires collaboration amongst nurses and a range of other healthcare professionals ${ }^{1}$ (Canary \& Wilkins, 2016; Meade et al., 2016), however interprofessional interactions and routines related to discharge vary within and across hospitals due to patient, professional and organizational factors. While regularly scheduled meetings and referral processes are commonly practiced, particular details such as their timing and structure, type of information shared, and who leads and attends varies (Bhamidipati et al., 2016; Duner, 2013; Goldman et al., 2015; Johannessen \& Steihaug, 2014; O'Leary, Killarney, et al., 2016; Waring, Bishop, \& Marshall, 2016; Waring et al., 2014). Workplaces where different professional and stakeholder perspectives are brought together in discharge planning and that value face-to-face and interpersonal interactions, have been found to have better shared understandings about patient care and coordination, and to generate more comprehensive discharge plans (Waring et al., 2014). General internal medicine (GIM) units have high volumes of patient admissions with the concomitant pressures of patient flow (Gilfillan, Newnham, Nagappan, Evans, \& Compton, 2016; Szecket, Wong, Wu, Berman, \& Morra, 2012). These units have been characterized as extremely busy workplaces with high professional stress, burnout and time pressures (Linzer et al., 2016). Discharge planning in GIM units can be particularly complex given the multifaceted and challenging nature of patients’ healthcare needs and the range of healthcare professionals involved in their care.

\footnotetext{
${ }^{1}$ Interprofessional collaboration has been defined as the "process of developing and maintaining effective interprofessional working relationships with learners, practitioners, patients/clients/families and communities to enable optimal health outcomes” (Canadian Interprofessional Health Collaborative, 2010).
} 
Over the last few decades, health care systems in Western countries, such as, Australia, Canada, United Kingdom and United States, have witnessed an expansion of management influence over professional activities. A managerial approach that has emphasized task completion and outcomes in the pursuit of evidence based, cost effective and efficient care is dominant (Beck \& Melo, 2014; Ferlie \& Fitzgerald, 2002). This approach is affecting the range of professional groups in GIM, and healthcare more broadly, as they defend or adapt their professional boundaries and roles to these demands (Correia, 2013; Harvey, Thompson, Pearson, Willis, \& Toffoli, 2017; Henderson, Willis, Toffoli, Hamilton, \& Blackman, 2016; Newman \& Lawler, 2009; Reeves, Nelson, \& Zwarenstein, 2008; Shannon \& French, 2005). For example, social workers, pharmacists, occupational therapists and physiotherapists in GIM units have experienced changes in their roles in the healthcare division of labour with greater emphasis on discharge-related responsibilities (Galati, Wong, Morra, \& Wu, 2011; Goldman et al., 2016; Neeman et al., 2017). Physicians in these settings have pressures to prioritize their decision making around patient flow with an increasing emphasis on the value of teaching residents about safe discharge (Greysen, Schiliro, Horwitz, Curry, \& Bradley, 2012; Schoenborn \& Christmas, 2013). New discharge professional roles have been created to facilitate admissions and discharge in acute care medical units (Okoniewska et al., 2015). Nurses in managerial roles across a range of hospitals units have engaged in "organizing work" that entails sophisticated technical, organizational and social skills (Allen, 2014); this has also been reported in the GIM context (Goldman et al., 2016). Challenging questions remain about the professional role of the nurse bedside carer in current healthcare systems (Allen, 2014, 2015; Heartfield, 2005). Bedside nurses' training in holistic, 
relational and personalized care can be seen to be in tension with the emphasis on technical work and the physical and coordinating care demands required to support patient flow (Feo \& Kitson, 2016; Wong, 2004)· Indeed, nurses experience conflict between care as an art and care as a financial target (Harvey et al., 2017). Changes for bedside nurses have been conceptualized as a focus on "task and time” rather than “thinking and linking” (Kitson, Muntlin Athlin, \& Conroy, 2014).

Changing professional roles in relation to discharge have implications for interprofessional interactions in discharge and quality of discharge planning. For example, physicians' needs to prioritize patient flow can lead to tensions in their interactions with nurses and other healthcare professionals around discharge (Goldman et al., 2016). Social workers, physiotherapists and occupational therapists' expertise in discharge planning can increase their involvement in discharge decision-making. Interprofessional interactions concerning discharge in GIM occur amidst longer-standing challenges with collaboration, in particular physician-nurse interactions (Lewin \& Reeves, 2011; Liu, Manias, \& Gerdtz, 2014; O'Leary, Ritter, et al., 2010; Reeves \& Lewin, 2004; Reeves et al., 2008; Reeves et al., 2009; Wu et al., 2013). Face to face communication between nurses and physicians has been shown to be limited in nature, and the increase in the proportion of communication that occurs by email or web-based communication has introduced further challenges (Smith et al., 2012; Wu et al., 2015; Wu et al., 2013). For example, nurses and physicians have expressed concerns about the nature of information shared, responsiveness limitations, and that electronic communication is not ideal for complex messages (Wu et al., 2015). Limited 
communication between physicians and nurses can impact their agreement on the plan of care for patients (O'Leary, Thompson, et al., 2010).

Given this context, our paper aims to extend understanding of bedside nurses’ roles in discharge collaboration in GIM. The findings are from a study of interprofessional collaboration and discharge in a GIM unit. This paper follows two other publications from this study that used the sociological theories of medical dominance and negotiated order to analyze the data. In the first publication the authors reported on factors that shape interactions between medical residents and other health care professionals in relation to patient discharge with implications for health professions education and quality of care (Goldman et al., 2015). The second publication explored the existence of, and interplay between, structural factors and microlevel practices in interprofessional interactions related to discharge (Goldman et al., 2016). While this paper noted the limited involvement of bedside nurses in discharge planning and decision making, the focus of the paper was on the range of healthcare professionals involved and the different opportunities for interprofessional negotiations. The authors wanted to focus more explicitly on the findings of bedside nurses' limited involvement in interprofessional collaboration in relation to discharge and therefore wrote this paper to provide a new analysis of these findings which can be positioned within the literature on nurse-physician interactions and the current context of nursing care.

\section{Methods}

An ethnographic approach was used in this study. Ethnography is concerned with the everyday experiences of individuals, organizations, and society, with a commitment 
to understanding the cultural context in which these experiences and social interactions take place (Emerson, Fretz, \& Shaw, 2011). This study draws upon Hammersley and Atkinson’s (2007) key features of ethnographic research. The study aimed to explore the social practice of interprofessional collaboration in a general internal medicine context with attention to the connections to patient safety and quality of care. The authors set out to collect data in the field rather than rely solely on individuals' interpretations of their behaviours and experiences. One unit was chosen as the focus of study to facilitate an indepth study, and a range of data sources typical of ethnography, largely observation and formal and informal interviews, were used. The first author (JG) collected data from January 2012 to May 2013. It was expected that the initial research question would evolve and be refined over time, with data collection beginning in a relatively unstructured manner and becoming more focused over time. Initial entrance into the field was with a broad interest in interprofessional collaboration in GIM. This research interest became more focused on interprofessional collaboration and discharge as the early observations demonstrated the prominence of discharge to healthcare professionals' day to day practices. Throughout data collection and coding, the authors refined one stream of analysis and interpretation to bedside nurses and interprofessional collaboration given the research team's interests in bringing further attention to this theme in our data. The research team consisted of individuals with nursing, medical and medical sociology backgrounds, and each brought different clinical and theoretical perspectives to data collection, analysis and interpretation. The aim of this paper is to use ethnography to provide detailed accounts of the experience and perspectives of bedside nurses and other healthcare professionals working in a GIM unit concerning interprofessional 
collaboration and discharge. The data are positioned within the socio-historical context of managerialism in healthcare and the nursing profession. The authors aim to produce knowledge to draw attention to practices in one unit which can combine together with other research to drive changes and improvements in nursing and interprofessional care.

Research ethics approval was obtained from the hospital research ethics board and affiliated university.

\section{Study setting}

The study was conducted in the GIM unit of an academic teaching hospital in Canada. This unit, which spanned two floors in the hospital, provided care for patients with complicated medical problems and follow-up for patients discharged from emergency departments and medical and surgical wards. At the time of data collection, the ward admitted approximately three-hundred and fifty patients per month and had approximately fifty to seventy nurses, sixteen medical residents (postgraduate medical trainees), twelve attending physicians (the physician responsible for the medical team), four social workers, pharmacists and community care access centre case managers (responsible for provision of home care and managing placement process into long-term care homes; may have training in social work or another health field), three physiotherapists and occupational therapists, and a speech-language pathologist, dietitian and spiritual care worker. The nursing group included two nurse managers, patient care coordinators and clinical nurse specialists, and the bedside nurses. A core group of bedside nurses most regularly took turns being in-charge nurses. Nurses provided care over a twenty-four hour period, seven days per week, in rotating shifts of twelve hours in 
length. The ward is a designated medical clinical teaching unit (CTU), and was composed of four medical teams and a fifth hospitalist team. Each medical team included one attending physician and senior resident, two or more junior residents, and two to four students. The hospital patient flow and utilization of care coordinators (patient flow coordinators), who had nursing backgrounds, worked with all hospital units.

Formal interprofessional care rounds organized to improve patient flow and discharge planning occurred weekday mornings. Rounds occurred every weekday in a meeting room on the unit, beginning at 9:00 am. Participants included the medical staff, residents, and students, nurse managers, in-charge nurses and nursing patient care coordinators, occupational therapists, physiotherapists, social workers, pharmacists, and less frequently speech language pathologist, dietitian and spiritual care worker. In addition, the patient flow coordinator and community care access coordinators attended. The rounds were organized into five fifteen-minute sessions. Each fifteen minute time period was dedicated to one of the five medical teams. A social worker, occupational therapist, physiotherapist, and pharmacist aligned with that medical team attended rounds during the same time period. The nursing group, consisting of the nurse managers, patient care coordinators and charge nurses, and the patient flow coordinator, attended rounds for the entire seventy-five minute time period. Bedside nurses did not participate.

\section{Data collection}

The observations were undertaken covering both formal and informal activities, including daily interprofessional, medical and nursing rounds, monthly interprofessional and patient safety rounds, interactions at nursing stations, and shadowing of clinicians. Observations focused on verbal and non-verbal interprofessional interactions about 
discharge planning as well as general collaborative practice issues. Observations of intraprofessional interactions were also collected when pertinent to discharge. In total, approximately 65 hours of fieldwork data were gathered, covering different times during the weekday from 7:00 am to 4:30 pm. The observations were largely undertaken during the daytime when the range of healthcare providers was most likely working in the unit and there was activity concerning discharge. Handwritten field notes were made during the observations; as soon as possible afterwards the notes were typed up with greater detail including asides, commentaries, and analytic memos (Emerson et al., 2011; Hammersley \& Atkinson, 2007).

One-to-one semi-structured interviews were conducted following an initial 3month period of observations and then continued during the study period. The interviews involved questions about individuals' perceptions of their own and others' roles concerning discharge, the discharge process, interprofessional interactions during discharge, and organizational discharge policies. A purposive maximum variation sampling approach (Patton, 2002) was used with the aim to interview individuals representing each professional group working in GIM. Interview participants were selected based on their professional group from the staff directory and recommendations made by participants. Twenty-three interviews, including one interview with two participants and four follow-up interviews, were conducted. Participants consisted of five nurses (three in leadership positions; two bedside nurses); three staff physicians; two medical residents (junior physicians); two social workers; two patient flow and utilization of care coordinators (with nursing background); and one physiotherapist, occupational therapist, pharmacist, speech language pathologist, community service case manager, and 
spiritual care worker. Two healthcare providers invited to participate in an interview did not respond. The sampling and timing of interviews were based on emerging ideas about the findings and relationships amongst concepts (Gobo, 2007). All interviews were audio recorded and transcribed verbatim.

\section{Analysis}

Data collection and analysis occurred iteratively. The research team met regularly during the data collection process to reflect on emerging themes and plan for future observations and interviews accordingly. The data for this paper were coded using a conventional and directed content analysis approach (Hsieh \& Shannon, 2005). An initial conventional content analysis approach allowed for an inductive approach where the codes and categories emerge from the data. In the subsequent directed content analysis approach, the literature on GIM nurse-physician collaboration as well as the nursing and managerialism literature was used to further extend the analysis and interpretation. During the analysis, data and method triangulation allowed for the development of a more comprehensive understanding of the phenomena of nursing collaboration in discharge in GIM (Flick, 1992; Kitto, Chesters, \& Grbich, 2008). While interviews with nurses were a key strand of data in the study sample, interviews with their colleagues from other professional groups provided important perspectives about nursing's role in discharge in GIM, with the observation data offering rich empirical insights to the actual professional and interprofessional behaviours in this setting.

\section{Findings}

The results are presented in three sections. The first section describes the nursing representation in interprofessional rounds and implications for knowledge sharing and 
bedside nurses' engagement. The second section reports on the processes of information sharing from rounds to bedside nurses. The third section describes the nature of nurses' interactions with physicians and other healthcare providers during the day, and the consequences in terms of nursing work and quality of discharge.

\section{Nursing and discharge communication: Interprofessional rounds}

It was found that structured interprofessional care rounds had been implemented in the GIM unit with the aim of improving operational efficiency and quality of care. While there was no formal name for the rounds, a number of study participants suggested that they should be called “discharge rounds" (Nurse, Interview \#18) given that much talk focused around patients’ discharge. The nurse managers, patient care coordinators and charge nurses represented the bedside nurses at these rounds with the patient care coordinators and charge nurses being mainly responsible for bringing nursing issues forward. This arrangement gave rise to concerns about nursing information available to share in rounds; information that was perceived to be valued during rounds; and variability in opportunities for nursing input during rounds.

The information available for the patient care coordinators and charge nurses to share was gathered from written or verbal reports received from bedside nurses prior to the rounds; the quality and consistency of this information was perceived to be variable by the nurses and physicians which had implications for information sharing and decision-making. The patient care coordinators and charge nurses acknowledged limitations with their representative role since they were not familiar with all of the patients; potential resulting problems with communication were observed in rounds. This 
extract illustrates gaps between medical expectations for information during rounds and the information available to charge nurses to share at this time:

A physician asks the nurses "How was her....level?” The charge nurse looks in binder and says "I don’t know, (nurses) didn’t say anything to me but they're still doing it.” The physician comments that this information would be helpful to get [...] so can use it to make decisions. (Fieldnote, Jan 28 2013)

The nursing leadership aim to minimize these information gaps, yet it was challenging given the number of patients and the limitations with information sharing:

...Let's say they're waiting to wean them off the oxygen, we have our nursing ....report sheets that we go through in rounds and we do ask for specific information but it doesn't always get transferred, they don't always write all the things that we want. (Nurse, Interview \#16)

...We would prefer the nurses themselves are there, we'd like them to be part of the team, that would be choice A no doubt....it is the person that knows them but who has the least input...but the input itself like it's very dependent on the patient care coordinator or the reports... (Nurse, Interview \#10)

The bedside nurses noted that information could change over the course of the time that rounds occur, which was another challenge to rounds being away from the patient's bedside without the input of the bedside nurse:

Nurse tells me that they are discussing patients in rounds now without having updates on patients. She says they should be having rounds around the patient and getting the nurses' input into the care plan. I ask her about the nurses passing on information to the charge nurse to take to rounds and she says that the in-charge [nurse] is gone already to rounds so can't give updates if patient status changes. (Fieldnote, Feb 27 2013)

Given time constraints, the interactions during rounds tended to be brief. The nurses and other healthcare professionals described tensions regarding the type of information that was perceived to be 'of value' for nurses to share during rounds. The nurses felt that "nursing issues" were "pushed to be talked outside of rounds" (Nurse, Interview \#18). While observations showed numerous instances of physicians seeking 
nursing input, the nurses at times felt that physicians and other healthcare professionals did not acknowledge their expertise:

Do you think they're [the patients] ready to go home? Like are they walking, going to the washroom, doing their ADLs (activities of daily living) etc.? And if someone brings up that question they'll (physicians) often say oh physio can you assess them whereas...I'm reading the nurses notes right here, they're doing everything independently, they're not needing assistance with anything. Oh can you still assess them, it’s like why? What's the point? (Nurse, Interview \#10)

However, observations showed that information shared by the nurses could often change a decision about a patient's discharge:

Nurse says he (referring to patient being discussed) couldn't walk, does he need an ambulance? Physiotherapist says do you want us to go see him? Physician says please. Nurse says we need to sort this out. Physician says we should change the discharge to afternoon to sort this out. (Fieldnote, Feb 7 2012)

Nurse says patient is agitated and confused.

Physician says so maybe won’t be going home so quickly. (Fieldnote, Jan 29 2013)

While efforts were made to include nursing input to the rounds, the bedside nurses did not participate in these interprofessional discussions:

... we have rounds that don't include the nurse that's taking care of the patient, they've made a decision, they come out, the decision is told what it is, if you as a nurse don’t agree, most nurses get frustrated (Nurse, Interview \#8)

The nursing leadership had worked to restructure the rounds to secure more nursing involvement. While other healthcare professionals acknowledged the importance of bedside nursing input at rounds, the nurse leadership explained that they had not yet been successful given the challenges of coordinating amongst all the healthcare professionals and concerns about nurses being away from their patients, as illustrated in the following extract:

We were trying to get all the nurses in, for years we've been trying to get... the primary nurse to come into rounds but it's a bit of a challenge because of 
the time that they have to commit to being in rounds. The coverage. (Nurse, Interview \#16)

\section{Discharge information exchange from rounds to bedside nurses}

Observational data indicated that the information discussed in the rounds was communicated to the bedside nurses through the electronic whiteboard and the charge nurse and patient care coordinator. These electronic and face-to-face strategies had their challenges in terms of information transfer, and both were characterized by a one-way flow of information, limiting bedside nurses’ participation in interprofessional discussions and decision-making.

It was found that the whiteboard's details about patient status were partly dependent on an individual inputting information during rounds, and were limited to the nature of information captured on the board. In addition, while this information could be helpful for bedside nurses to see patient discharge information immediately following rounds, it was not as effective later in the day since it was not routinely updated.

Each GIM floor had its own nurse manager and patient care coordinator, who had developed different processes for verbally communicating information to bedside nurses following rounds. One floor relied on the patient care coordinator and charge nurse to relay information to the nurses in an ad-hoc in-person one-to-one approach. At times, this did not occur until partway through the day, and the nurses sometimes had already received the information through other means:

...some days whenever I see them I'll just try to catch them and give them the information but some nurses are quite busy and I understand so sometimes the information that I need to pass on to them they've already gotten it...let's say for tests or procedures the ward clerk will inform them or even the doctor may speak to them... (Nurse, Interview \#7) 
In contrast, the other floor had regularly scheduled 'post-rounds' with the nurses.

However, not all nurses were able to attend the post-rounds, and observations showed that nurses came in and out of the room during the meeting time. The information tended to flow from the patient care coordinator and charge nurse to the nurses in a reporting style. The following fieldnote is an excerpt of an observation of the in-charge nurse giving a brief report on each patient:

(Patient A) is for discharge today or tomorrow.

(Patient B) also is for discharge today or tomorrow, going to be reassessing. (Patient C) still working on pain management

(Patient D) talking about PCU (palliative care), going to discuss that

(Patient E) discharge today, ambulance booked for 1:00

(Patient F) reassessing today, may be ready for discharge

(Fieldnote, Jan 29 2013)

If the nurses had questions about the discussion or decisions made during rounds, there was limited opportunity to address any concerns or disagreements that arose given that the other healthcare professionals were not present:

Nurse says patient's blood pressure is still really high.

Patient care coordinator and charge nurse say that they didn't say a word in rounds. (Fieldnote, Feb 27 2013)

Formal and informal processes were in place to enable communication from the rounds to the bedside nurses. However, as indicated above, this communication was variable and nurses were recipients of information rather than engaged in information exchange and decision-making:

...they're (nurses) left out of the equation a lot, and I'm not sure that builds fond relationships in terms of respecting each other. It sets up an environment of well I'll say this to someone but my opinion doesn't really count. (Nurse, Interview $\# 10)$

\section{Nursing interprofessional discharge communication: post rounds}


Patient care plans often changed following rounds, and interview and observation data indicated the lack of a formal structure for this updated information to be communicated to the nurses. Information sharing about discharge between the residents and nurses, and between the occupational therapists, physiotherapists, pharmacists, social workers and nurses were dependent on the individual's initiative and specific information requirements. These communication patterns had implications for the patient flow coordinator as an intermediary, as well as for nurses' understanding of patient discharge information, which ultimately impact upon nursing engagement and quality of patient discharge.

Residents and medical students were expected to be in communication with the patient's nurse although that was up to the individual residents to learn and manage. Information sharing was "individually based and hit or miss" (Nurse, Interview \#10). The following example shows the impromptu nature of these exchanges as well as the role of the ward clerk in communication between nurses and physicians:

The ward clerk says to a nurse that the physician wants to know if can give meds before the patient goes. The nurse says she already gave. The physician overhears and makes a comment and says thank you. The nurse then talks directly to the physician (Fieldnote, Jan 31 2012)

The occupational therapists, physiotherapists, social workers and pharmacists reported in their interviews that they needed to seek out nursing input during the day. For these professionals, the nurses were recognized as accurate and reliable sources of knowledge about changes in a patient's status. With this knowledge from the nurses, these professionals noted that they were in better position to share details that can affect discharge plans. However, there were perceptions amongst the nurses that this was not necessarily reflective of a collaborative approach: 
I think that if you talk to any of the nurses about collaboration they'd say what collaboration? It's not existing...People talk about things because they need to get a job done, a task done and that's when they may talk to somebody from another profession when they want a task done or they want to discuss something that they have a specific concern about but there's no avenue for nursing to sit and have collaboration rounds. (Nurse, Interview \#18)

The limited direct interaction between the residents and nurses had implications

for the patient flow coordinators responsible for expediting patient admissions and

discharge. These individuals had to play a coordination role between the two professional groups given that the residents and bedside nurses were "never in the same room together, very rarely":

Because time and time again you'll talk to the nurse on the floor and she's like I don't know why they think that one's going because they're having this issue. It's like, oh well, does the doctor know that? They're like, well I haven’t seen the...I think that (unclear) happens frequently. (Patient flow coordinator, Interview \#4)

Residents acknowledged limitations with communicating with the nurses about

discharge; a resident commented that at times residents may resist creating an expectation

for timing of discharge to minimize tension with the nurses if the physicians get busy and cannot meet the time expectations:

if you're planning on discharging a patient generally you will tell the nurse although I know I'm guilty of this myself doing everything, telling the patient yup, we've just put the discharge order they're going home now and they're like what do you mean they're going home now? And you know sometimes you kind of think well I mean they're going home now because this is when I had time to write the discharge summary. (Medical resident, Interview \#14)

Nurses described limitations in regards to their understanding of what the patient issues are in relation to discharge planning, sometimes not knowing a patient is being discharged that day or not knowing plans for the next few days. The nurses experienced difficulties when they had to be the in-between person for the patient/family and 
physicians concerning discharge, and their limited resources to manage the different requests and needs:

Sometimes you have an idea as to why the discharge is held up but most of the time you really don't know or it might be where the doctor will say to the patient you're going home at 4:00...in charge or the nurse who should know has no clue you're going home. Really? What time did they tell you you're going home?... and then sometimes it just happens where oh, did you tell this patient they're going home at such and such a time. Oh yes, but they're not going home anymore. (Nurse, Interview \#11)

It was stressed that the culmination of these nursing issues impacted on nurses' work and on their perception of their role on the interprofessional team:

Upon discharge, they [the nurses] don't feel that they're in the loop...so there is a lot of disengagement... because they're not included so they don't want to be included anymore so they don't seek out to know what's going on. There are always individuals who are very self directed... but there are a lot of people who will pass over and not try to even find out any of that information anymore because they don't feel that they're part of the team...they don't feel that their voice is appreciated or heard. (Nurse, Interview \#8)

\section{Discussion}

This study provides insights on the limited engagement of bedside nurses in interprofessional collaboration and discharge planning in the GIM unit, and the implications for nursing work and patient discharge. For the GIM unit studied, morning rounds in a room separate from the patients had been structured to allow for an interprofessional approach to discharge planning, yet bedside nurses were absent. Furthermore, the flow of information from rounds through nursing leaders to the bedside nurses limited nurses' involvement in decision-making and collaboration with the other healthcare professionals, and in particular the physician group responsible for discharge. These limitations with nursing involvement in discharge planning were also apparent throughout the day, and were perceived to impact the quality of discharge. 
Scheduling challenges in organizing interprofessional discharge planning rounds is not unique to nursing (Waring et al., 2016). However, the absence of bedside nurses in rounds may be linked not merely to scheduling logistics but to a broader professional issue whereby bedside nursing work is largely seen as the collection, coordination and dissemination of information for other team members, with a consequent devaluing of bedside nurses’ time for meetings, connecting, processing and analyzing information (Kitson et al., 2014; Lavander, Merilainen, \& Turkki, 2016). The inclusion of nurse managers, patient care coordinators and in-charge nurses in rounds demonstrates an effort at nursing representation, yet limiting interprofessional collaboration to nursing leadership should not be assumed to reflect optimal communication or patient care practices (Cott, 1997). The tensions that existed in the sharing of nursing information in rounds can be positioned alongside other research findings that nurses, and other professionals, had difficulties getting their voice heard in discharge planning due to dominance of decision making focused on medical issues, underlying interprofessional hierarchies and pressures to expedite hospital discharge (Miller et al., 2008; Reeves, Lewin, Espin \& Zwarenstein, 2010; Waring et al., 2016). Efforts to improve interprofessional collaboration and patient-centered care have led to studies of bedside interprofessional rounds (Gonzalo, Kuperman, Lehman, \& Haidet, 2014; O'Leary, Killarney, et al., 2016). These rounds involved two physicians and a nurse or other care provider discussing the case at the patient's bedside, potentially allowing for patient involvement; however, other healthcare professionals were not involved. Further, and regular, explicit attention to the purpose and outcomes of interprofessional rounds and 
how they fit into larger organizational improvement efforts is needed (Liu et al., 2014; O'Leary, Johnson, \& Auerbach, 2016; Prystajecky, Lee, Abonyi, Perry \& Ward, 2017).

The electronic whiteboard, and the patient care coordinator and in-charge nurse, were the two main strategies used to transfer discharge planning information from rounds to the bedside nurses. Both of these strategies had limitations in terms of timeliness but more strikingly, they did not provide for opportunities for bedside nurses to engage in discussion and decision-making. The practice of this one-way flow of information may reflect changing professional roles in response to discharge priorities. Nursing work is increasingly being conceptualized in the literature, and supported by data from this study, as technical and physical work in contrast to relational and person-centred care. Nurses' role in discharge is therefore being viewed in terms of their support for bed management rather than in the provision of holistic care (Wong, 2004). The devaluing of the fundamentals of care performed by nurses, along with a lack of recognition of its impact on patient outcomes (Feo \& Kitson, 2016; MacMillan, 2016) may be particularly relevant in the GIM setting where this type of care may be a more defining aspect of nursing work. Overlooking this unmeasured care and the opportunities for bedside nurses to inform discharge decision-making may be compromising the goal of high quality discharge.

The continued challenges of nursing communication with physicians and other healthcare providers during the day can be positioned within the increasing reliance on electronic communication, including the greater use of text rather than face to face interactions between nurses and physicians, and the resulting tensions due to varied perceptions about clinical prioritization and expected response times (Quan et al., 2013; 
Wu et al., 2013). Having healthcare providers informally seek out nurses’ input during the day contributes to a task-focused orientation, and may be substituting for a collaborative approach to patient discharge planning. The devaluing of nursing input to patient assessments for discharge during the day is surprising given inpatients' needs for nursing observation and care and the reported role of the bedside nurse in discharge related patient progress assessment, patient teaching, and interprofessional communication (Foust, 2007; Propp et al., 2010). Furthermore, the scant information flowing back to them so that they are often the last to know of discharges can negatively impact on patient/family experience. Overall, this lack of bedside nursing involvement has the potential to increase chance of readmissions.

The limitations of this study are that the data were gathered from one GIM unit in an urban academic teaching hospital in Canada. This limits the transferability of findings, as the organization of nursing, medical and other healthcare professional personnel, and the rounding and interprofessional structures and routines, are likely to differ in other hospitals. Also, the sampling strategy aimed to capture a range of professional perspectives and it is possible that further interviews with nurses would have contributed additional insights into the themes presented. However, despite these limitations and the fact that data for this study were collected in 2012-2013, discharge pressures, limited resources and increasing numbers of patient admissions, continue to be a dominant focus in healthcare (El-Eid, Kaddoum, Tamim, \& Hitti, 2015; Institute for Healthcare Improvement, 2017; Qin, Thompson, Bogomolov, Ward, \& Hakendorf, 2017), and so implications presented in this paper are likely relevant in broader discussions of nursing, interprofessional collaboration and discharge. 


\section{Concluding comments}

This study builds upon previous research of nurse-physician collaboration in GIM, managerialism in health care and nursing work, and hospital discharge and quality of care. The tremendous pressures facing hospitals, in particular GIM units, for efficient patient admission and discharge, are contributing to the organization of work, and the professional and interprofessional interactions to support these processes. However, these study findings which have illuminated the absence of bedside nurses in interprofessional interactions and decision making in discharge in the unit studied demand further attention regarding the implications for patient safety and quality of care, and nursing work. The bedside nurse is perceived as being utilized as support personnel and not as part of the team - a potential waste of the intellectual capital of nurses and their contribution to discharge planning.

Interprofessional education and practice interventions are offered as ways to improve interprofessional collaboration involving nurses with colleagues from other professions. Interprofessional education ${ }^{2}$ aims to improve individuals' attitudes, knowledge, skills and behaviours for collaborative practice, by, for example, improving healthcare professionals' understandings of each others’ role and overcoming negative relations, which may then lead to improve health care practice (Reeves et al., 2016). Findings demonstrating a lack of clarity concerning discharge roles in an acute care internal medicine teaching unit (Card, Ward, Chipperfield, \& Sheppard 2014) reveal the

\footnotetext{
${ }^{2}$ Interprofessional education has been defined as "occasions when two or more health/social care professions learn with, from and about each other to improve collaboration and the quality of care" (CAIPE 2002).
} 
need for interprofessional education to help improve shared understanding. However, while interprofessional education can lead to improvements in attitudes/perceptions and collaborative knowledge and skills, there is less evidence of its effectiveness on behavioural and organizational practice changes (Reeves et al., 2016). Interprofessional practice interventions (Reeves, Pelone, Harrison, Goldman, \& Zwarenstein, 2017) involving nurses with other professional groups provide an additional strategy to improve interprofessional collaboration and patient care. These interventions include bedside rounding, geographic localization of medical teams to wards, and team-based care models (e.g. Dunn et al., 2017; Gausvik, Lautar, Miller, Palleria, \& Schlaudecker, 2015; Hastings, Suter, Bloom \& Sharma, 2016; Henkin et al., 2016; Huang et al., 2017). Findings from studies of these interventions show positive developments, however further research is needed with attention to both their anticipated and unanticipated consequences. Furthermore, further progress will require attention to the structural hierarchical relations that exist between nursing and medicine and that influence their interactions (Reeves et al., 2010).

These study findings provide insights to one GIM unit in Canada, but illuminates the importance of such in-depth studies across clinical units and hospitals nationally and internationally to better understand how interprofessional collaboration, and more specifically, nurse-physician interactions in discharge, vary across care settings. These indepth and comparison studies would allow deeper insights into the contextual factors that shape interprofessional negotiations (Liberati, 2017). In addition, further research is needed to examine the effects of education and practice-based interventions that aim to improve opportunities for interprofessional collaboration and discharge. This research, 
though, needs to consider the broader professional structures and cultures that play a critical role in interprofessional collaboration, discharge planning and patient care.

Acknowledgements: We would like to thank the GIM staff that participated in the interviews and observations in this research. This research was funded by the Canadian Institutes of Health Research through a Frederick Banting and Charles Best Canada Graduate Scholarship Doctoral Award.

\section{References}

Allen, D. (2014). Re-conceptualising holism in the contemporary nursing mandate: From individual to organisational relationships. Social Science \& Medicine, 119, 131138.

Allen, D. (2015). Inside 'bed management': Ethnographic insights from the vantage point of UK hospital nurses. Sociology of Health \& Illness, 37, 370-384.

Beck, M., \& Melo, S. (2014). Quality management and managerialism in healthcare: A critical historical survey. UK: Palgrave Macmillan.

Bhamidipati, V.S., Elliott, D.J., Justice, E.M., Belleh, E., Sonnad, S.S., \& Robinson, E.J. (2016). Structure and outcomes of interdisciplinary rounds in hospitalized medicine patients: A systematic review and suggested taxonomy. Journal of Hospital Medicine, 11, 513-523.

CAIPE. (2002). Interprofessional education: a definition. London: CAIPE. 
Canadian Interprofessional Health Collaborative. (2010). A national interprofessional competency framework. Retrieved from http://www.cihc.ca/files/CIHC_IPCompetencies_Feb1210.pdf

Canary, H.E., \& Wilkins, V. (2017). Beyond hospital discharge mechanics: Managing the discharge paradox and bridging the care chasm. Qualitative Health Research, 27, $1225-1235$.

Card, S.E., Ward, H.A., Chipperfield, D., \& Sheppard, M.S. (2014). Postgraduate internal medicine residents' roles at patient discharge - do their perceived roles and perceptions by other health care providers correlate? Journal of Interprofessional Care, 28, 76-78.

Correia, T. (2013). The interplay between managerialism and medical professionalism in hospital organisations from the doctors' perspective: A comparison of two distinctive medical units. Health Sociology Review, 22, 255-267.

Cott, C. (1997). "We decide, you carry it out": A social network analysis of multidisciplinary long-term care teams. Social Science \& Medicine, 45, 14111421.

Duner, A. (2013). Care planning and decision-making in teams in Swedish elderly care: A study of interprofessional collaboration and professional boundaries. Journal of Interprofessional Care, 27, 246-253.

Dunn, A.S., Reyna, M. Radbill, B., Parides, M. Colgan, C. Osio, T.,...Kaplan, H. (2017). The impact of bedside interdisciplinary rounds on length of stay and complications. Journal of Hospital Medicine, 12, 137-142. 
El-Eid, G.R., Kaddoum, R., Tamim, H., \& Hitti, E.A. (2015). Improving hospital discharge time: A successful implementation of Six Sigma methodology. Medicine (Baltimore), 94, e633.

Emerson, R.M., Fretz, R.I., \& Shaw, L.L. (2011). Writing ethnographic fieldnotes (2nd ed.). Chicago: University of Chicago Press.

Feo, R., \& Kitson, A. (2016). Promoting patient-centred fundamental care in acute healthcare systems. International Journal of Nursing Studies, 57, 1-11.

Ferlie, E., \& Fitzgerald, L. (2002). The sustainability of the New Public Management in the UK. In K. McLaughlin, F. Ewan, \& S.P. Osborne (Eds.), New public management: Current trends and future prospects (pp. 341-352). London: Routledge.

Flick, U. (1992). Triangulation revisited: strategy of validation or alternative? Journal for the Theory of Social Behaviour, 22, 175-197.

Foust, J.B. (2007). Discharge planning as part of daily nursing practice. Applied Nursing Research, 20, 72-77.

Galati, M., Wong, H.J., Morra, D., \& Wu, R.C. (2011). An evidence-based case for the value of social workers in efficient hospital discharge. The Health Care Manager (Frederick), 30, 242-246.

Gausvik, C., Lautar, A., Miller, L., Palleria, H., Schlaudecker, J. (2015). Structured nursing communication on interdisciplinary acute care teams improves perceptions of safety, efficiency, understanding of care plan and teamwork as well as job satisfaction. Journal of Multidisciplinary Healthcare, 14, 33-37. 
Gilfillan, C., Newnham, E., Nagappan, R., Evans, J., \& Compton, J. (2016). A 7-day team-based model of care in general medicine: Implementation and outcomes at 12 months. Internal Medicine Journal, 46, 79-85.

Gobo, G. (2007). Sampling representativeness and generalizability. In C. Seale, G. Gobo, J.F. Gubrium, \& D. Silverman (Eds.), Qualitative research practice (pp. 405426). London: Sage Publications Ltd.

Goldman, J., Reeves, S., Wu, R., Silver, I., MacMillan, K., \& Kitto, S. (2015). Medical residents and interprofessional interactions in discharge: An ethnographic exploration of factors that affect negotiation. Journal of General Internal Medicine, 30, 1454-1460.

Goldman, J., Reeves, S., Wu, R., Silver, I., MacMillan, K., \& Kitto, S. (2016). A sociological exploration of the tensions related to interprofessional collaboration in acute-care discharge planning. Journal of Interprofessional Care, 30, 217-225.

Gonzalo, J.D., Kuperman, E., Lehman, E., \& Haidet, P. (2014). Bedside interprofessional rounds: Perceptions of benefits and barriers by internal medicine nursing staff, attending physicians, and housestaff physicians. Journal of Hospital Medicine, 9, 646-651.

Greysen, S.R., Schiliro, D., Horwitz, L.I., Curry, L., \& Bradley, E.H. (2012). "Out of sight, out of mind": Housestaff perceptions of quality-limiting factors in discharge care at teaching hospitals. Journal of Hospital Medicine, 7, 376-381.

Hammersley, M., \& Atkinson, P. (2007). Ethnography (3rd ed.). London: Routledge. Harvey, C., Thompson, S., Pearson, M., Willis, E., \& Toffoli, L. (2017). Missed nursing care as an 'art form': The contradictions of nurses as carers. Nursing Inquiry. 
Hastings, S.E., Suter, E., Bloom, J., Sharma, K. (2016). Introduction of a team-based care model in a general medical unit. BMC Health Services Research, 16, 245.

Heartfield, M. (2005). Regulating hospital use: Length of stay, beds and whiteboards. Nursing Inquiry, 12, 21-26.

Henderson, J., Willis, E., Toffoli, L., Hamilton, P., \& Blackman, I. (2016). The impact of rationing of health resources on capacity of Australian public sector nurses to deliver nursing care after-hours: a qualitative study. Nursing Inquiry, 23, 368-376.

Henkin, S., Chon, T.Y., Christopherson, M.L., Halvorsen, A.J., Worden, L.M., Ratelle, J.T. (2016). Improving nurse-physician teamwork through interprofessional bedside rounding. Journal of Multidisciplinary Healthcare, 9, 201-205.

Hsieh, H.F., \& Shannon, S.E. (2005). Three approaches to qualitative content analysis. Qualitative Health Research, 15, 1277-1288.

Huang, K.T., Minahan, J., Brita-Rossi, P., Aylward, P., Katz, J.T., Roy, C.,...Boxer, R. (2017). All together now: Impact of a regionalization and bedside rounding initiative on the efficiency and inclusiveness of clinical rounds. Journal of Hospital Medicine, 12, 150-156.

Institute for Healthcare Improvement. (2017). Try scheduling hospital discharges. Retrieved from http://www.ihi.org/resources/Pages/ImprovementStories/ImprovementTipTrySche dulingHospitalDischarges.aspx.

Johannessen, A.K., \& Steihaug, S. (2014). The significance of professional roles in collaboration on patients' transitions from hospital to home via an intermediate unit. Scandinavian Journal of Caring Sciences, 28, 364-372. 
Kitson, A.L., Muntlin Athlin, A., \& Conroy, T. (2014). Anything but basic: Nursing's challenge in meeting patients' fundamental care needs. Journal of Nursing Scholarship, 46, 331-339.

Kitto, S.C., Chesters, J., \& Grbich, C. (2008). Quality in qualitative research. Medical Journal of Australia, 188, 243-246.

Lewin, S., \& Reeves, S. (2011). Enacting ‘team’ and ‘teamwork’: Using Goffman’s theory of impression management to illuminate interprofessional collaboration on hospital wards. Social Science \& Medicine, 72, 1595-1602.

Lavander, P., Merilainen, M., \& Turkki, L. (2016). Working time use and division of labour among nurses and health-care workers in hospitals - a systematic review. Journal of Nursing Management, 24, 1027-1040.

Liberati, E.G. (2017). Separating, replacing, intersecting: The influence of context on the construction of the medical-nursing boundary. Social Science \& Medicine, 172, 135-143.

Linzer, M., Poplau, S., Babbott, S., Collins, T., Guzman-Corrales, L., Menk, J., . . . Ovington, K. (2016). Worklife and wellness in academic general internal medicine: Results from a national survey. Journal of General Internal Medicine, 31, 1004-1010.

Liu, W., Manias, B., \& Gerdtz, M. (2014). Medication communication through documentation in medical wards: Knowledge and power relations. Nursing Inquiry, 21, 246-258.

MacMillan, K. (2016). The hidden curriculum: What are we actually teaching about the fundamentals of care? Nurings Leadersh (Tor Ont), 29, 37-46. 
Meade, L.B., Suddarth, K.H., Jones, R.R., Zaas, A.K., Albanese, T., Yamazaki, K., \& O'Malley, C.W. (2016). Patients, nurses, and physicians working together to develop a discharge entrustable professional activity assessment tool. Academic Medicine, 91, 1388-1391.

Miller, K.L., Reeves, S., Zwarenstein, M., Beales, J.D., Kenaszchuk, C., \& Conn, L.G. (2008). Nursing emotion work and interprofessional collaboration in general internal medicine wards: A qualitative study. Journal of Advanced Nursing, 64, 332-343.

Neeman, M., Dobrinas, M., Maurer, S., Tagan, D., Sautebin, A., Blanc, A.L., \& Widmer, N. (2017). Transition of care: A set of pharmaceutical interventions improves hospital discharge prescriptions from an internal medicine ward. European Jouranl of Internal Medicine, 38, 30-37.

Newman, S., \& Lawler, J. (2009). Managing health care under new public management: A Sisyphean challenge for nursing. Journal of Sociology, 45, 419-432.

O'Leary, K.J., Johnson, J.K., \& Auerbach, A.D. (2016). Do interdisciplinary rounds improve patient outcomes? Only if they improve teamwork. Journal of Hospital Medicine, 11, 524-525.

O'Leary, K.J., Killarney, A., Hansen, L.O., Jones, S., Malladi, M., Marks, K., \& M Shah, S. (2016). Effect of patient-centred bedside rounds on hospitalised patients' decision control, activation and satisfaction with care. BMJ Quality \& Safety, 25, 921-928. 
O'Leary, K.J., Ritter, C.D., Wheeler, H., Szekendi, M.K., Brinton, T.S., \& Williams, M.V. (2010). Teamwork on inpatient medical units: Assessing attitudes and barriers. Quality \& Safety in Health Care, 19, 117-121.

O'Leary, K.J., Thompson, J.A., Landler, M.P., Kulkarni, N., Haviley, C., Hahn, K., . . Williams, M.V. (2010). Patterns of nurse-physician communication and agreement on the plan of care. Quality \& Safety in Health Care, 19, 195-199.

Okoniewska, B., Santana, M. J., Groshaus, H., Stajkovic, S., Cowles, J., Chakrovorty, D., \& Ghali, W.A. (2015). Barriers to discharge in an acute care medical teaching unit: a qualitative analysis of health providers' perceptions. Journal of Multidisciplinary Healthcare, 8, 83-89.

Patton, M.Q. (2002). Qualitative research and evaluation methods (3rd ed.). Thousand Oaks, CA: Sage Publications, Inc.

Propp, K.M., Apker, J., Zabava Ford, W.S., Wallace, N., Serbenski, M., \& Hofmeister, N. (2010). Meeting the complex needs of the health care team: Identification of nurse-team communication practices perceived to enhance patient outcomes. Qualitative Health Research, 20, 15-28.

Prystajecky, M., Lee, T., Abonyi, S., Perry, R., \& Ward, H. (2017). A case study of healthcare providers’ goals during interprofessional rounds. Journal of Interprofessional Care, 31, 463-469.

Qin, S., Thompson, C., Bogomolov, T., Ward, D., \& Hakendorf, P. (2017). Hospital occupancy and discharge strategies - a simulation based study. Internal Medicine Journal. 
Quan, S.D., Wu, R.C., Rossos, P.G., Arany, T., Groe, S., Morra, D., . . Lau, F. Y. (2013). It's not about pager replacement: An in-depth look at the interprofessional nature of communication in healthcare. Journal of Hospital Medicine, 8, 137-143.

Reeves, S., Fletcher, S., Barr, H., Birch, I., Boet, S., Davies, N., McFadyen, A., Rivera, J., Kitto, S. (2016). A BEME systematic review of the effects of interprofessional education: BEME Guide No. 39. Medical Teacher, 38, 656-668.

Reeves, S., \& Lewin, S. (2004). Interprofessional collaboration in the hospital: Strategies and meanings. Journal of Health Services Research \& Policy, 9, 218-225.

Reeves, S., Lewin, S., Espin, S., \& Zwarenstein, M. (2010). Interprofessional teamwork for health and social care. London, UK: Blackwell-Wiley.

Reeves, S., Nelson, S., \& Zwarenstein, M. (2008). The doctor-nurse game in the age of interprofessional care: A view from Canada. Nursing Inquiry, 15, 1-2.

Reeves, S., Pelone, F., Harrison, R., Goldman, J., \& Zwarenstein, M. (2017).

Interprofessional collaboration to improve professional practice and healthcare outcomes. Cochrane Database of Systematic Reviews, Jun 22;6:CD000072. doi: 10.1002/14651858.CD000072.pub3.

Reeves, S., Rice, K., Conn, L.G., Miller, K.L., Kenaszchuk, C., \& Zwarenstein, M. (2009). Interprofessional interaction, negotiation and non-negotiation on general internal medicine wards. Journal of Interprofessional Care, 23, 633-645.

Schoenborn, N.L., \& Christmas, C. (2013). Getting out of silos: An innovative transitional care curriculum for internal medicine residents through experiential interdisciplinary learning. Journal of Graduate Medical Education, 5, 681-685. 
Shannon, V., \& French, S. (2005). The impact of the re-engineered world of health-care in Canada on nursing and patient outcomes. Nursing Inquiry, 12, 231-239.

Smith, C.N., Quan, S.D., Morra, D., Rossos, P.G., Khatibi, H., Lo, V., . . . Wu, R.C. (2012). Understanding interprofessional communication: a content analysis of email communications between doctors and nurses. Applied Clinical Informatics, 3, 38-51.

Szecket, N., Wong, H. J., Wu, R.C., Berman, H.D., \& Morra, D. (2012). Implementation of a continuous admission model reduces the length of stay of patients on an internal medicine clinical teaching unit. Journal of Hospital Medicine, 7, 55-59.

Waring, J., Bishop, S., \& Marshall, F. (2016). A qualitative study of professional and carer perceptions of the threats to safe hospital discharge for stroke and hip fracture patients in the English National Health Service. BMC Health Services Research, 16, 297.

Waring, J., Marshall, F., Bishop, S., Sahota, O., Walker, M., Currie, G., . . . Avery, T. (2014). An ethnographic study of knowledge sharing across the boundaries between care processes, services and organisations: The contributions to 'safe' hospital discharge Health Services and Delivery Research.

Wong, W.H. (2004). Caring holistically within new managerialism. Nursing Inquiry, 11, $2-13$.

Wu, R., Lo, V., Morra, D., Appel, E., Arany, T., Curiale, B., . . Quan, S. (2015). A smartphone-enabled communication system to improve hospital communication: Usage and perceptions of medical trainees and nurses on general internal medicine wards. Journal of Hospital Medicine, 10, 83-89. 
Wu, R.C., Lo, V., Morra, D., Wong, B.M., Sargeant, R., Locke, K., . . . Cheung, M. (2013). The intended and unintended consequences of communication systems on general internal medicine inpatient care delivery: A prospective observational case study of five teaching hospitals. Journal of the American Medical Informatics Association, 20, 766-777. 